\title{
Kinetic Determination of Indium Ion Based on the B-Z Oscillating Chemical System
}

\author{
Jinzhang Gao, * Lei Wang, Wu Yang and Fuwei Yang
}

\author{
Chemistry \& Chemical Engineering College, Northwest Normal University, Lanzhou 730070, P. R. China
}

\begin{abstract}
Este trabalho trata da aplicação do sistema químico oscilante B-Z catalisado por cério, na determinação do íon índio em solução aquosa, baseada na sua perturbação linear sobre o período oscilante. Os resultados mostraram que a alteração no período oscilante é linearmente proporcional à concentração do íon índio, no intervalo de $4,98 \times 10^{-7}$ a $3,85 \times 10^{-6} \mathrm{~mol} \mathrm{~L}^{-1}$, com coeficiente de correlação de 0,9984 e limite de detecção de $4,96 \times 10^{-7} \mathrm{~mol} \mathrm{~L}^{-1}$, sob condições ótimas. Vários fatores influentes na determinação foram também examinados e o mecanismo de determinação foi discutido.
\end{abstract}

The present paper deals with the application of cerium-catalyzed B-Z oscillating chemical system to the determination of indium ion in aqueous solution based on its linear perturbation on the oscillating period. Results showed that the change in the oscillating period is linearly proportional to the concentration of indium ion in the range from $4.98 \times 10^{-7}$ to $3.85 \times 10^{-6} \mathrm{~mol} \mathrm{~L}^{-1}$, with a correlation coefficient of 0.9984 and a detection limit of $4.96 \times 10^{-7} \mathrm{~mol} \mathrm{~L}^{-1}$ under the optimum conditions. Various influencing factors on the determination were also examined and the determination mechanism was discussed.

Keywords: indium ion, B-Z oscillating chemical system, kinetic determination

\section{Introduction}

Some far-from-equilibrium reaction systems exhibit an oscillating behavior that involves amplitude or periodic changes in the concentration of some ingredients in space or with time. ${ }^{1}$ Such systems are often called oscillating chemical reactions. Oscillating chemical system is interesting because it may serve as a simple chemical model of biological processes, such as heartbeat, breath, even the sleep cycle. ${ }^{2}$ Many researchers have studied most of such reaction systems and proposed theoretical models accounting for the experimental results from the physicochemical point of view in order to elucidate the complex reaction mechanisms. ${ }^{2}$

Recently, the application of oscillating chemical reactions for the determination of trace amounts of substance has gained some interest from the analytical chemists because of its instrumental simplicity and high sensitivity. ${ }^{2,3}$ The well-known oscillating chemical systems are the Belousov-Zhabotinskii (BZ) reaction and the copper-catalyzed oscillating system. ${ }^{4}$ For the analytical purpose, the most extensively studied oscillating reaction

* e-mail: jzgao@nwnu.edu.cn system used is the Belousov-Zhabotinskii (BZ) reaction, which involves the oxidation of malonic acid by bromate ion in acid media and catalyzed by traces of transition metal ions that possess two oxidation states differing a single electron, whether in free form or as complexes. When the BZ reaction occurs, a regular potential oscillation (with time) can be recorded through an electrochemical instrument. If an analyte is introduced into the BZ system, the characteristics of oscillating including the oscillation period, amplitude, induction time, the largest Lyapunov exponent and so on can be perturbed. In some cases, the perturbation exhibits in a linear manner with the analyte, and this perturbation can be used as an analytical parameter. Previous studies have shown that many organics such as polyphenols, hydroquinone, benzidine, ninhydrin or ascorbic acid can perturb the BZ reaction in a linear manner, with concentrations or logarithm of concentrations. ${ }^{4-9}$ These results indicated that $\mathrm{B}-\mathrm{Z}$ reaction is a useful analytical tool for the direct determination of trace amounts of organic compounds. While, the use of $\mathrm{BZ}$ reaction for determination of metallic ions has less been reported. ${ }^{10-12}$

In a survey of the oscillation effect, it was found that indium ion could significantly increase the period of the $\mathrm{BZ}$ reaction. In addition, this perturbation effect of indium 
ion on the BZ system exhibited a perfect linear relationship (period change $v s$. indium ion concentration) in the range from $4.98 \times 10^{-7}$ to $3.85 \times 10^{-6} \mathrm{~mol} \mathrm{~L}^{-1}$. Therefore, an attempt was made to apply $\mathrm{BZ}$ reaction to the determination of indium in this work.

\section{Experimental}

\section{Apparatus}

The experimental assembly consisted of an oscillation reactor (ca.50 mL) and a potential measuring system. The reactor was coupled with a Model 501 thermostat and a Model ML-902 magnetic stirrer to keep the system at $303 \pm 0.5 \mathrm{~K}$. A CHI-832 (CHI, USA) analyzer was connected to the reactor through two Pt-working electrodes and $\mathrm{K}_{2} \mathrm{SO}_{4}$ reference electrode to record the potential changes. A Type 302 bromide selective electrode was used to measure the change of bromide ion concentration.

\section{Reagents}

All chemicals including $\mathrm{KBrO}_{3}$, malonic acid, $\mathrm{KBr}$, $\mathrm{H}_{2} \mathrm{SO}_{4}, \mathrm{Ce}(\mathrm{IV})$ salt and $\mathrm{In}$ (III) (in the form of nitrate) were of analytical-reagent grade and used as received. All stock solutions of them were prepared separately in doubly distilled water and used throughout.

\section{Procedure}

$6.5 \mathrm{~mL}$ of $0.2 \mathrm{~mol} \mathrm{~L}^{-1} \mathrm{KBrO}_{3}, 6.5 \mathrm{~mL}$ of $0.5 \mathrm{~mol} \mathrm{~L}^{-1}$ malonic acid and $1.0 \mathrm{~mL}$ of $0.04 \mathrm{~mol} \mathrm{~L}^{-1} \mathrm{Ce}(\mathrm{IV})$ were loaded in a $50 \mathrm{~mL}$ water-jacket reactor. After the solution was homogeneous by continuous stirring and reached thermal equilibrium, $6 \mathrm{~mL}$ of $\mathrm{H}_{2} \mathrm{SO}_{4}$ solution $\left(0.8 \mathrm{~mol} \mathrm{~L}^{-1}\right)$ was added to the mixture. Meanwhile, the indicator, counter and reference electrodes were immersed into the reaction media and the data acquisition started. When the oscillation amplitude and period stabilized, a few micro-liters of working solution containing various amounts of indium ion were injected at the moment the platinum electrode potential dropped to the minimum. Then a calibration curve of period increase against the concentration of indium ion added was plotted. The above conditions were considered as the standard except that in the investigation of experimental variables.

\section{Results and Discussion}

When indium ion was injected to the reaction medium, the period of the oscillating immediately increased. Figure 1 shows the typical potential oscillation profiles for the oscillating chemical system both in the absence and presence of indium ion perturbation. Since the addition of indium ion changed the oscillating period significantly, a variational ratio of period $\left(\mathrm{P}_{\mathrm{R}}\right)$ was chosen as an analytical signal, which is defined as:

$\mathrm{P}_{\mathrm{R}}=\Delta \mathrm{T} / \mathrm{T}_{0}=\left(\mathrm{T}-\mathrm{T}_{0}\right) / \mathrm{T}_{0}$

where $\mathrm{T}_{0}$ and $\mathrm{T}$ represent the periods of the oscillation before and after indium ion injection, respectively, and it was found that $\mathrm{P}_{\mathrm{R}}$ changed linearly to the concentration of indium ion under certain operating conditions. So, the perturbation of period can be applied to the indium ion determination.
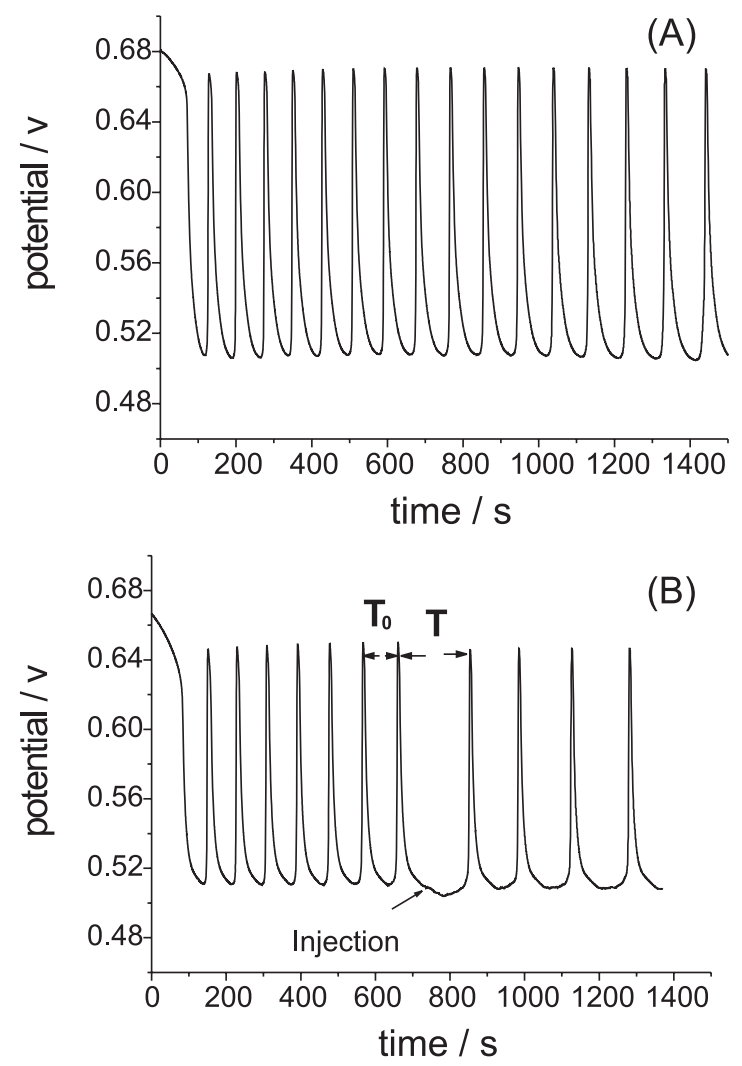

Figure 1. Typical mixed potential oscillation profiles: (A) in the absence of In(III); (B) in the presence of $1.96 \times 10^{-6} \mathrm{~mol} \mathrm{~L}^{-1} \mathrm{In}$ (III). Common conditions: $\mathrm{KBrO}_{3}, 0.065 \mathrm{~mol} \mathrm{~L}^{-1} ; \mathrm{CH}_{2}(\mathrm{COOH})_{2}, 0.1625 \mathrm{~mol} \mathrm{~L}^{-1}$; $\mathrm{Ce}(\mathrm{IV})$, $0.002 \mathrm{~mol} \mathrm{~L}^{-1} ; \mathrm{H}_{2} \mathrm{SO}_{4}, 0.24 \mathrm{~mol} \mathrm{~L}^{-1}$.

In order to ensure the maximum possible sensitivity and accuracy in the determination of In(III), the effects of experimental variables on the determination were examined respectively.

Influences of experimental variables on indium determination

The effect of $\mathrm{KBrO}_{3}$ concentration was studied in the range of $0.055-0.07 \mathrm{~mol} \mathrm{~L}^{-1}$. With the increase of $\mathrm{KBrO}_{3}$ 
concentration, the response of In(III) perturbation decreased (Figure 2A), with the amplitude, frequency increased and the induction period shortened. When the concentration of $\mathrm{KBrO}_{3}$ was less than $0.055 \mathrm{~mol} \mathrm{~L}^{-1}$, the oscillation profiles became unstable. For the stable and sensitive purposes, the optimal choice of $\mathrm{KBrO}_{3}$ concentration was $0.055 \mathrm{~mol} \mathrm{~L}^{-1}$.

Figure 2B showed that higher concentration of malonic acid caused a higher $P_{R}$ value over the range from 0.125 $0.175 \mathrm{~mol} \mathrm{~L}^{-1}$, whereas decreased when the concentration further increased. We adopted $0.375 \mathrm{~mol} \mathrm{~L}^{-1}$ as optimal malonic acid concentration.

The concentration of $\mathrm{Ce}(\mathrm{IV})$, which was considered as a catalyst, was studied in the range of 0.0012-0.0028 mol $\mathrm{L}^{-1}$. The results showed that the sensitivity of In(III) got maximum when $\mathrm{Ce}(\mathrm{IV})$ concentration was $0.002 \mathrm{~mol} \mathrm{~L}^{-1}$.

As can be seen in Figure $2 \mathrm{D}, \mathrm{P}_{\mathrm{R}}$ increased and then decreased with the increase of acidity. $0.23 \mathrm{~mol} \mathrm{~L}^{-1}$ of sulfuric acid was chosen as the optimum in this work.

The influence of temperature was investigated over the range $293 \mathrm{~K}-313 \mathrm{~K}$. In the absence of $\mathrm{In}(\mathrm{III})$, the oscillation period decreased with the increase in temperature. However, temperature scarcely affected the response of the oscillating system to the perturbation. $303 \mathrm{~K}$ was chosen in order to work with a suitable oscillating period for the determination of In(III).
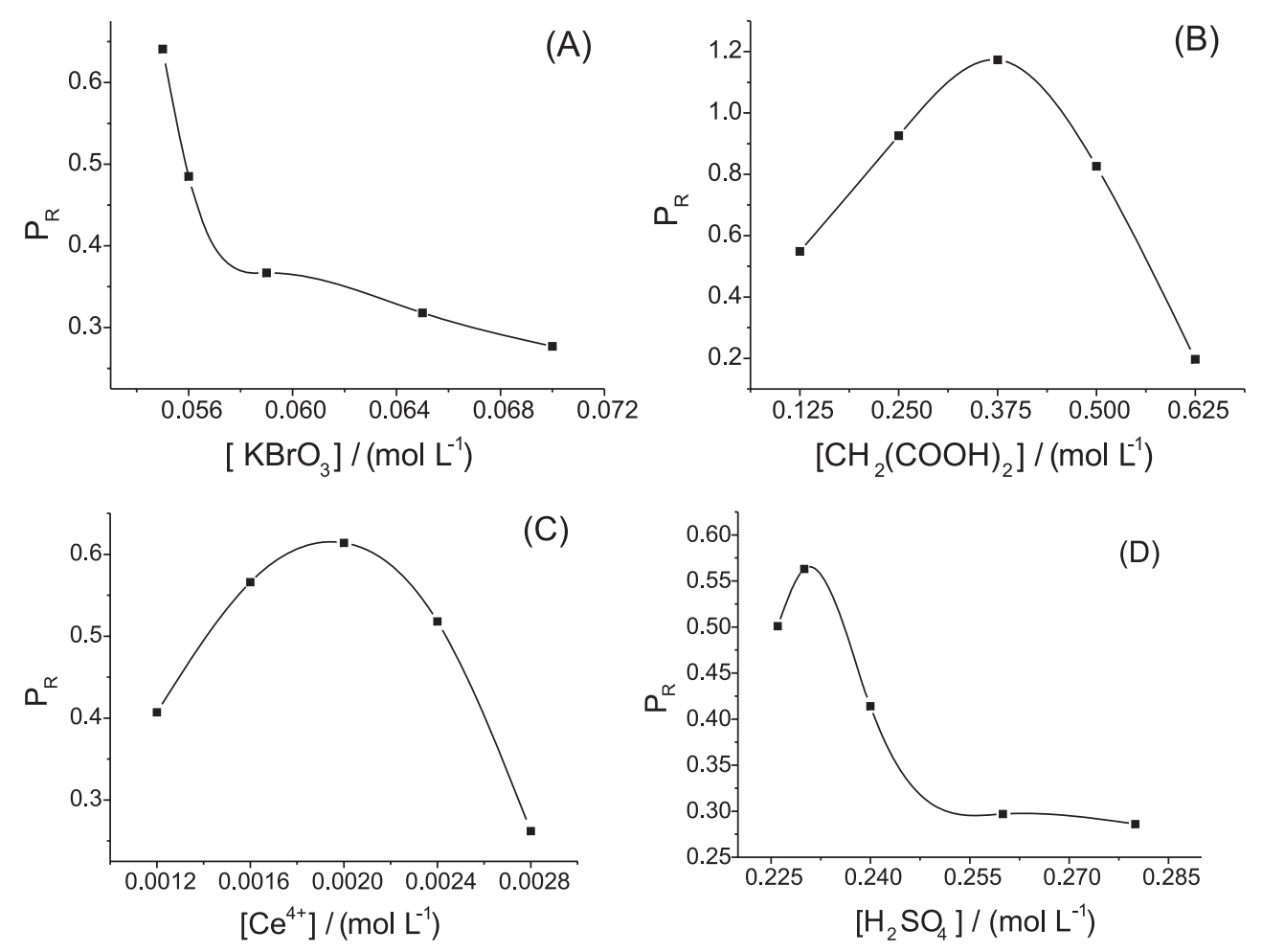

Figure 2. Influence of concentration of (A) $\mathrm{KBrO}_{3}$; (B) $\mathrm{CH}_{2}(\mathrm{COOH})_{2}$; (C) $\mathrm{Ce}(\mathrm{IV})$; (D) $\mathrm{H}_{2} \mathrm{SO}_{4}$ on the In(III) perturbed oscillating reaction. Common condition: $[\operatorname{In}(\mathrm{III})]=1.96 \times 10^{-6} \mathrm{~mol} \mathrm{~L}{ }^{-1}$. 


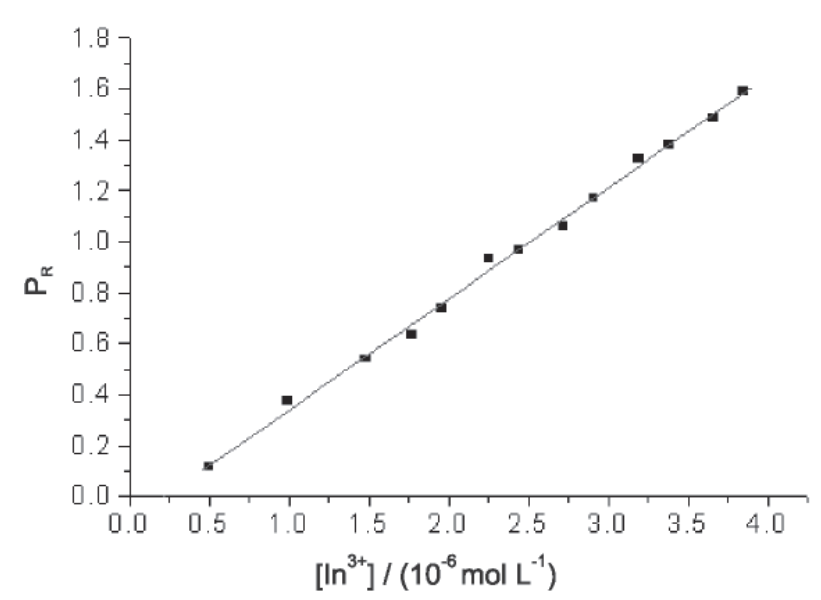

Figure 3. Calibration curve of the $\mathrm{P}_{\mathrm{R}}$ versus concentrations of $\mathrm{In}(\mathrm{III})$ in the range of $4.98 \times 10^{-7}-3.85 \times 10^{-6} \mathrm{~mol} \mathrm{~L}^{-1}$. When the concentration of In(III) was over theis range, no linearity was obtained (not shown in the figure).

the $\mathrm{In}(\mathrm{III})$ determination at the concentrations of 3000 -fold that of $\mathrm{In}(\mathrm{III}) ; \mathrm{Ca}^{2+}, \mathrm{Ba}^{2+}, \mathrm{Cu}^{2+}$ and $\mathrm{Mn}^{2+}$ did not interfere with the In(III) determination at the concentrations of 1000fold; $\mathrm{F}^{-}, \mathrm{Ag}^{+}, \mathrm{Fe}^{2+}, \mathrm{Fe}^{3+}$ did not interfere with the indium determination at the concentrations of 200 -fold. While $\mathrm{Cl}^{-}$ and $\mathrm{I}^{-}$have potential interference for indium determination with the tolerance limits of 10-fold. Therefore, higher concentrations of $\mathrm{Cl}^{-}$and $\mathrm{I}^{-}$should be eliminated from the solution. These findings showed that the BZ reaction system is a useful tool for indium determination.

\section{Possible mechanism for indium ion determination}

The FKN mechanism, which is referred to as bromide controlled, supplies a basic form of the chemistry for understanding and modeling the oscillatory phenomena. According to this theory, there are two states (reduced and oxidized) available to the $\mathrm{B}-\mathrm{Z}$ reaction depending on the bromide concentration. A simplified interpretation of this system with many kinetic steps including several independent variables could involve three overall reactions. $^{13}$

Process I:

$\mathrm{BrO}_{3}^{-}+2 \mathrm{Br}^{-}+3 \mathrm{CH}_{2}(\mathrm{COOH})_{2}+3 \mathrm{H}^{+} \rightarrow 3 \mathrm{BrCH}(\mathrm{COOH})_{2}$ $+3 \mathrm{H}_{2} \mathrm{O}$

Process II:

$\mathrm{BrO}_{3}^{-}+4 \mathrm{Ce}^{3+}+5 \mathrm{H}^{+} \rightarrow \mathrm{HOBr}+4 \mathrm{Ce}^{4+}+2 \mathrm{H}_{2} \mathrm{O}$

Process III:

$\mathrm{BrCH}(\mathrm{COOH})_{2}+4 \mathrm{Ce}^{4+}+\mathrm{HOBr}+\mathrm{H}_{2} \mathrm{O} \rightarrow 2 \mathrm{Br}^{-}+3 \mathrm{CO}_{2} \uparrow$ $+4 \mathrm{Ce}^{3+}+6 \mathrm{H}^{+}$
When the bromide level is high the reduced state (Process I) is dominant where the rate-controlling step is the medium reaction: $\mathrm{Br}^{-}+\mathrm{BrO}_{3}^{-}+2 \mathrm{H}^{+} \rightarrow \mathrm{HBrO}_{2}+\mathrm{HOBr}$. The bromination of malonic acid causing removal of $\mathrm{Br}^{-}$ simultaneously, the reduced state becomes unstable when $\left[\mathrm{Br}^{-}\right]$becomes sufficiently low allowing the autocatalytic reaction to take over and oxidize $\mathrm{Ce}^{3+}$ to $\mathrm{Ce}^{4+}$, in which the reaction: $\mathrm{HBrO}_{2}+\mathrm{BrO}_{3}^{-}+\mathrm{H}^{+} \rightarrow 2 \mathrm{BrO}_{2}$ is the ratecontrolling step. Process II is characterized by high concentrations of $\mathrm{HBrO}_{2}, \mathrm{Ce}^{4+}$ and organic radicals. Then the regeneration of bromide by $\mathrm{Ce}^{4+}$ oxidation of brominated organic compounds grows up in Process III. When [Brjumps to a high level and the concentration of $\mathrm{HBrO}_{2}$ reached the level in Process I, the cycle started again.

By the aid of bromide ion-selective electrode, we got the periodical changes of bromide concentration during the reaction. Figure 4 shows an apparent single oscillating cycle of $\left[\mathrm{Br}^{-}\right]$. The top value of $\left[\mathrm{Br}^{-}\right]$at point $\mathrm{A}$ first decreases slightly down to point $\mathrm{B}$ and then decreases sharply until point $\mathrm{C}$, and increases slowly to point $\mathrm{D}$, and finally, increased abruptly to the level of point A, causing the start of another cycle. At the points A, B, C and D, there are some switches of main steps in the reaction.

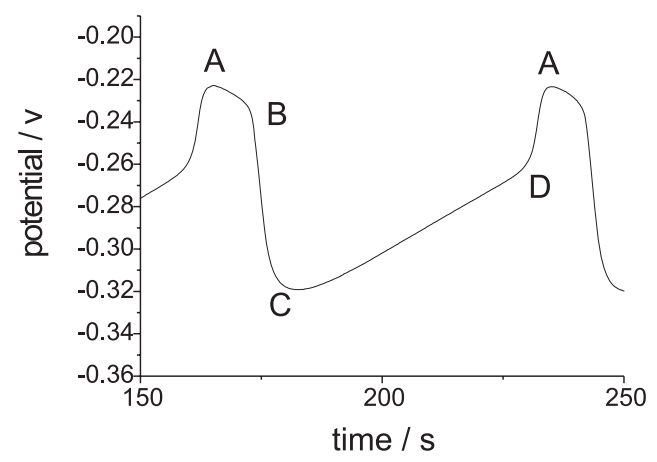

Figure 4. Single oscillating cycle of $\left[\mathrm{Br}^{-}\right]$.

In order to bring this problem to an understanding, we put the injection into the system at different points, and found that the maximum perturbation appeared when the injecting $\mathrm{In}^{3+}$ was in the period of C-D, during which bromide concentration increased slightly. It appears that $\mathrm{In}^{3+}$ affect the system strongly in the period of bromide regeneration. Introducing micro quantity of $\operatorname{In}^{3+}$ caused the increasing of bromide concentration in the system, showing the lengthen oscillation period simultaneously.

\section{Conclusions}

Indium is widely used in the semiconductor industry. The high quality requires the high precise analytical techniques. At present, the most used method for indium determination is atom absorbance spectrometry. Of course, 
this method is very sensitive, however, the time-consuming and energy-consuming brought some troubles with operation. The proposed method in this work gives a potential to solve this problem. The results showed that the change in oscillating period is linearly proportional to the concentration of indium ion over the range of $4.98 \times 10^{-7}$ to $3.85 \times 10^{-6}$ mol $\mathrm{L}^{-1}$, with a correlation coefficient of 0.9984 .

\section{Acknowledgments}

This work was supported in part by the Project of International Cooperation between China and Ukraine (043-05), the National Natural Science Foundation (20475044) and the Invention Project of Science \& Technology (KJCXGC-01, NWNU), China.

\section{References}

1. Field, R. J.; Schnieder, F. W.; J. Chem. Educ. 1989, 66, 195.

2. Jimenez-Prieto, R.; Silva, M.; Pwewzi, D. B.; Analyst 1998, 123, 1R.

3. Gao, J.Z.; Pak. J. Biolog. Sci. 2005, 8, 512.
4. Gao, J.Z.; Yang, H; Liu, X.H.; Ren, J; Li, Q.Z.; Kang, J.W.; Talanta 2002, 57, 105.

5. Toledo, R.; Silva, M.; Khavrus, V.O.; Strizhak, P.E.; Talanta 2000, 125, 2118.

6. Gao J.Z.; Ren, J.; Yang, W.; Liu X.H.; Yang, H.; Li, Q.Z.; Deng, H.L.; J. Electroanal. Chem. 2002, 520, 157.

7. Raoof, J. B.; Ojani, R.; Kiani, A.; Khosravi, M.; Adnani, A.; Bull. Chem. Soc. Jpn. 2005, 78, 256.

8. Gao, J.Z.; Sou, N.; Yang, W.; Wang, L.; Zhao, G.H.; Sun, K.J.; Chin. J. Anal. Lab. (Ch.) 2004, 23, 5.

9. Gao, J.Z.; Yang, H.; Liu, X.H.; Ren, J.; Lu, X.Q.; Hou, J.G.; Kang, J.W.; Talanta 2001, 55, 99.

10. Tikhonova, L.P.; Zakrevskaya, L.N.; Yasimirskii, K.B.; J. Anal. Chem. 1978, 33, 1991.

11. Strizhak, P. E.; Didenko, O. Z.; Ivashchenko, T. S.; Anal. Chim. Acta 2000, 428, 15.

12. Raoof, J.; Ojani, R.; Kiani, A.; Anal. Sci. 2004, 20, 883.

13. Nicholas, J.T.; George, K.; Victor F.A.L.; Lyons, J.; J. Am. Chem. Soc. 1972, 94, 4.

Received: June 21, 2005 Published on the web: March 3, 2006 